\title{
Marcas y redes de generación de valor en el sector ovino del País Vasco
}

\section{Brands and value delivery networks in the lamb sector of the Basque Country}

\author{
José Juan Beristain OÑederra ${ }^{1}$ \\ Lucía Mediano Serrano \\ Jone Mitxeo Grajirena ${ }^{1}$ \\ Javier Villalba Merlo ${ }^{1}$ \\ Universidad del País Vasco (España)
}

Recibido el23 de diciembre de 2010, aceptado el 14 de junio de 2011

$\mathrm{N}^{\mathrm{o}}$ de clasificación JEL: M31

DOI: $10.5295 / \mathrm{cdg} .100274 \mathrm{jb}$

\section{Resumen:}

El presente trabajo trata de determinar el potencial que subyace en la marca como instrumento generador de valor para el sector ovino vasco, y analiza en qué medida el sector está aprovechando ese potencial. El estudio parte de una revisión de la literatura relativa al valor percibido, las señales de información, las marcas y las redes de generación de valor. Seguidamente, se realiza un análisis empírico del sector ovino vasco, recurriendo tanto a fuentes de información primarias como secundarias. Los resultados obtenidos ponen de relieve las oportunidades que brinda la marca al sector ovino vasco para proporcionar un mayor valor a los consumidores e incrementar su competitividad.

Palabras clave:

Gestión de marcas; sector ovino; cadena de valor, competitividad.

\begin{abstract}
:
This work seeks to determine the potential of the brand as a tool that can create value for the lamb sector of the Basque Country, and analyzes to what extend the sector is taking advantage of that potential. To achieve this goal, we carry out a revision of the literature related to perceived value, information signals, brands and value delivery networks. After that, we make an empirical analysis of the Basque lamb sector, resorting to primary and secondary sources of information. The results show the chance offered by the brand to increase value for customers and enhance the competitiveness of the sector.
\end{abstract}

\section{Keywords:}

Brand management, lamb sector, value chain, competitiveness.

\footnotetext{
${ }^{1}$ Facultad de Ciencias Económicas y Empresariales (Unidad Delegada de San Sebastián) Plaza de Oñati, 1; 20.018 Donostia-San Sebastián.josejuan.beristain@ehu.es, lucia.mediano@ehu.es, jone.mitxeo@ehu.es, javier.villalba@ehu.es
} 


\section{INTRODUCCIÓN}

El sector agrario representa menos del 1\% del PIB del País Vasco. No obstante, a pesar de su reducido tamaño, goza de la consideración de "estratégico" (Ley 17/2008, de 23 de diciembre, de Política Agraria y Alimentaria), debido a su repercusión social, medioambiental y cultural.

Este sector está atravesando actualmente por un momento difícil, debido, entre otros factores, a la falta de valoración de la actividad agrícola y ganadera en una sociedad cada vez más terciarizada, la reducción de ingresos de sus productores que ven incrementados sus costes de producción y la disminución de las ayudas públicas.

Esta situación es también aplicable al sector del cordero del País Vasco, que se enfrenta, además, a una disminución del consumo y a una competencia externa cada vez más fuerte (Institut de l'élevage, 2008). Como consecuencia de ello, muchos operadores del sector ovino ven peligrar su futuro, a menos que se adopten medidas tendentes a incrementar su competitividad.

La presente investigación trata de responder en cierta medida a esta necesidad, realizando una aportación académica desde una perspectiva de marketing, y más específicamente de gestión de marcas. De hecho, la literatura de marketing señala a la marca como una herramienta estrechamente vinculada a la capacidad competitiva de las empresas, por su influencia en la valoración que los consumidores realizan de una determinada oferta del mercado. Esta relación es también aplicable a los mercados agroalimentarios, siendo considerada la marca como un instrumento útil para incrementar el valor percibido por los consumidores y, por ende, el valor generado para las empresas (Albayrak y Grunes, 2010). La literatura especializada señala, asimismo, que el valor de la marca está básicamente condicionado por las asociaciones mentales que ésta es capaz de suscitar (Aaker, 1991; Keller, 1993; Low y Lamb, 2000), destacando especialmente en el ámbito agroalimentario aquellas referentes a la calidad y el origen de los productos. Estas asociaciones, además, no conforman realidades independientes, dado que los consumidores, en muchos casos, emplean los atributos de origen para inferir el nivel de calidad del producto (Johansson y Nebenzahl, 1986; Juric y Worsley, 1998; Becker, 1999; Van Ittersum et al., 2001).

Partiendo de estas premisas, el presente trabajo estudia en qué medida se están explotando o podrían explotarse en el sector del cordero de raza Latxa (la raza predominante en el sector ovino vasco) las oportunidades que proporciona la marca para incrementar el valor percibido por los consumidores y, en última instancia, aumentar la competitividad del sector.

Para realizar este análisis, en primer lugar se examina el potencial que presenta la marca desde una perspectiva de generación de valor, y se identifican los factores clave que condicionan el aprovechamiento de ese potencial. A continuación, se describe la estructura del sector del cordero de raza Latxa del País Vasco, para, tomando como base dicha estructura, analizar las marcas existentes en el sector así como las redes de operadores a las que se vinculan. Por último, reflexionamos sobre el aprovechamiento del potencial de la marca que apreciamos en el sector, realizando determinadas propuestas dirigidas a favorecer la competitividad del mismo.

Esta investigación constituye una primera aproximación a la realidad de las marcas en el sector ovino de Euskadi, y ha sido desarrollada a partir del análisis de los operadores del 
sector y no de la demanda, la cual será analizada en un trabajo posterior ${ }^{1}$. Las fuentes de información empleadas para conocer el sector han sido tanto primarias (entrevistas con operadores, reuniones de grupo y observación directa) como secundarias (estadísticas oficiales y estudios del sector). El marco teórico que antecede al análisis empírico, por su parte, se nutre de una revisión bibliográfica relativa al valor percibido, las señales de información, las marcas y la cadena de valor.

\section{MARCO TEÓRICO}

La literatura de marketing señala que, para ser competitiva, la empresa debe proporcionar a sus clientes un mayor valor y satisfacción que sus competidores, dado que sólo así recibirá valor a cambio, ya sea en forma de ventas, de cuota de mercado o de beneficios actuales o futuros (Kotler y Armstrong, 2008). Este planteamiento parte de la base de que el proceso de decisión de compra del consumidor está determinado por la valoración que éste realiza de la amplia oferta de productos existente en el mercado, o dicho en otros términos, del valor percibido por el consumidor.

\subsection{El valor percibido por el consumidor}

El concepto de valor percibido es sumamente complejo, debido a su subjetividad (Barroso y Martín, 1999), lo que ha dado lugar a una falta de unanimidad sobre su definición. Algunos autores lo conciben como la capacidad de un producto para satisfacer deseos o la satisfacción global generada por un producto (Blackwell et al, 1999) o el vínculo emocional entre productor y consumidor (Butz y Goodstein, 1996). Otros, en cambio, lo consideran como la calidad percibida por el consumidor ajustada al precio relativo del producto (Doods y Monroe, 1985; Doyle, 1984).

Con todo, la definición más amplia y la que goza de mayor aceptación es aquella que concibe el valor percibido como "lo que se obtiene (calidad, conveniencia, beneficios emocionales, etc.) en función de lo que se da para adquirir y usar el producto (precio, riesgo, tiempo, esfuerzo, etc.)", considerados ambos en sentido amplio (Martin y Brown, 1990; Lassar et al., 1995).

No es extraño, por tanto, que la siguiente propuesta de Zeithaml (1988, p.14) se haya convertido en un referente en la literatura de marketing: "el valor percibido es la valoración global que hace el consumidor de la utilidad proporcionada por el producto, sobre la base de las percepciones en torno a lo que recibe y lo que da".

La utilidad a las que alude esta definición puede tener distinta naturaleza, tanto funcional como simbólica. La utilidad funcional está ligada a la parte práctica o racional del valor

\footnotetext{
${ }^{1}$ Este artículo ha sido realizado en el marco del proyecto de investigación "Análisis del sector del cordero lechal de oveja Latxa en la Comunidad Autónoma de Euskadi (C.A.E.): diagnóstico de la situación y estrategias de actuación". Dicho proyecto ha sido desarrollado dentro del Convenio de colaboración entre los Departamentos de Educación, Universidades e Investigación, Agricultura Pesca y Alimentación y la UPV/EHU, para la realización de acciones destinadas a la investigación, el desarrollo y la innovación tecnológica en los ámbitos agrario, forestal, pesquero y alimentario.
} 
y se deriva de atributos específicos del producto, atributos generales que sintetizan conjuntos de atributos específicos, como la calidad percibida, así como beneficios funcionales asociados al producto. En relación a la calidad percibida, resulta reseñable el consenso que existe en la comunidad científica al señalarla como un componente básico del valor (Aaker, 1991; Vahie y Paswan, 2006). No en vano, esta variable representa el juicio del consumidor sobre la excelencia o superioridad global del producto (Zeithaml, 1988), por lo que se puede convertir directamente en razón de compra para el consumidor (Aaker, 1991).

La utilidad simbólica, por su parte, se refiere a la parte emocional del valor y se refiere a los sentimientos suscitados por el producto, los cuales pueden desembocar en lazos afectivos y emocionales que tienen un efecto positivo en la lealtad de los consumidores.

Por otra parte, es preciso tener presente que los clientes se crean expectativas sobre el valor de un producto, de forma que en la medida en que el desempeño o valor percibido supera a las expectativas se genera una sensación de satisfacción que es esencial para lograr la fidelización de la clientela.

\subsection{Las señales emitidas al mercado}

Las expectativas del consumidor sobre el valor de un determinado producto, están condicionadas por distintas señales de información emitidas al mercado, siendo las referentes a la calidad del producto, junto con el precio, las que mayor atención reciben en la literatura de marketing, por su importancia, en el proceso de generación de valor y satisfacción del cliente (Oude Ophuis y Van Trijp, 1995).

Olson (1972) considera que, dado el carácter multidimensional y complejo de la calidad, el consumidor es incapaz de realizar una evaluación directa de la misma, por lo que selecciona un conjunto de atributos del producto que son utilizados como indicadores o señales de la calidad. Dichos atributos son clasificados por este autor en dos grupos: atributos intrínsecos y extrínsecos.

Los atributos intrínsecos son específicos de cada producto, están relacionados con sus características físicas (composición, sabor, color, textura, aroma, etc.), y no pueden ser modificados sin alterar las cualidades o naturaleza del producto. Dado su carácter específico, sólo se pueden establecer comparaciones entre los productos pertenecientes a la misma categoría. Los atributos extrínsecos, por su parte, están relacionados con el producto, pero no forman parte física del mismo. Entre ellos, cabe citar la marca, el etiquetado, el origen, el precio y el esfuerzo publicitario (Zeithaml, 1988) ${ }^{2}$.

Respecto a la importancia que, en términos generales, tienen los atributos intrínsecos y extrínsecos en la percepción de la calidad, diversos estudios (Darden y Schwinghammer, 1985; Olson y Jacoby, 1972; Szybillo y Jacoby, 1974) han concluido que los atributos intrínsecos juegan un papel más importante que los extrínsecos, por conferirles el consumidor una mayor fiabilidad como indicadores de calidad. Otros estudios (Calvo et al. 1998), no obstan-

\footnotetext{
${ }^{2}$ Existen algunos atributos, como el envase del producto, que son difíciles de clasificar como intrínsecos o extrínsecos, por lo que reciben el nombre de intermedios (Medina et al., 2001) El envase se podría considerar como atributo intrínseco cuando forma parte de la composición física del producto o como atributo extrínseco cuando desempeña una simple función de protección o comunicación. En ocasiones, el envase es considerado como un atributo intrínseco, pero la información que contiene, como atributo extrínseco (Zeithaml, 1988).
} 
te, han puesto de relieve que, los atributos extrínsecos pueden ser más importantes que los intrínsecos. En la actualidad la hipótesis más comúnmente aceptada supone que la calidad se percibe a través tanto de atributos intrínsecos como extrínsecos (Medina et al., 2001), dando más importancia a uno o a otros según la situación de que se trate. Así, los consumidores confiarán más en las características físicas del producto que en los atributos extrínsecos cuando piensan que son capaces de evaluar, con cierta seguridad, aquellas características que indican calidad y están altamente implicados en la decisión de compra (Sprott y Shimp, 2004).

Por otro lado, siguiendo el enfoque de la Economía de la Información, los atributos que intervienen en la percepción de la calidad han sido clasificados en tres grupos, en función del momento en el que el consumidor puede percibir y evaluar dichos atributos (Darby \& Karni, 1973; Cruz et al. 2004): atributos de búsqueda, de experiencia y de creencia.

Los atributos de búsqueda pueden ser evaluados por el consumidor antes de la compra del producto (por ejemplo, la apariencia de un producto), los atributos de experiencia sólo pueden ser evaluados después del consumo del producto (por ejemplo, el sabor del producto) y los atributos de creencia, finalmente, no pueden ser evaluados por el consumidor medio en circunstancias normales (por ejemplo, la salubridad de un producto), estando sometidos por tanto a su fe o confianza en la información proporcionada.

Obsérvese que las dos clasificaciones que acabamos de presentar no son mutuamente excluyentes. Es más, muchos de los modelos que tratan de explicar la percepción de la calidad por parte del consumidor y su proceso de decisión de compra, integran ambos enfoques (Steenkamp, 1989; Andersen 1994; Oude Ophuis y Van Trijp, 1995; Grunert et al., 1996; Poulsen et al., 1996; Northern, 2000).

En el ámbito alimentario, las interacciones existentes entre determinados atributos intrínsecos y extrínsecos y los atributos de experiencia han sido documentadas en diversos trabajos (Jacoby et al., 1971; Nevid, 1981; Oude Ophuis, 1994), poniendo de relieve la influencia de atributos intrínsecos, como la apariencia del producto, y extrínsecos, como la información proporcionada en el etiquetado, sobre determinados atributos de experiencia, como el sabor y la frescura del producto. Otros trabajos (Becker, 2000; Northen, 2000; Sepúlveda et al. 2010) señalan, por su parte, que los atributos extrínsecos, a diferencia de los intrínsecos, pueden comunicar no sólo atributos de experiencia, sino también atributos de creencia. Así, por ejemplo, el origen del producto (atributo de creencia), que es altamente valorado por el consumidor, sólo puede ser comunicado mediante el uso de indicadores extrínsecos como los distintivos de origen o marcas. Consecuentemente, los distintivos de distinta índole se han convertido en un medio cada vez más importante para enviar señales a los consumidores sobre el origen y la calidad de los productos.

\subsection{La marca como fuente de valor en el sector ovino}

Una vez delimitado el concepto de valor percibido y puesto de relieve el poder que las señales de información ejercen sobre el mismo, seguidamente nos centramos en aquellas señales que conforman el objeto de estudio de este trabajo (las marcas), circunscribiéndonos al sector agroalimentario y más específicamente al sector ovino.

La literatura de marketing señala que las marcas son un conjunto de signos distintivos (nombres y grafismos) que anuncian la existencia de una combinación específica de atribu- 
tos (Martín, 2005), haciendo así posible el reconocimiento y la diferenciación del producto (Keller, 1993), y reduciendo el riesgo percibido por el consumidor (Kapferer, 2008). Como resultado de todo ello, las marcas reducen el esfuerzo de compra (Ollé y Riu, 2009).

Obsérvese que, a través de estas funciones, las marcas proporcionan utilidad al consumidor, influyendo así en el valor percibido (Beristain, 2010), tal como explicamos seguidamente.

\section{A. La identificación y diferenciación del producto}

La marca anuncia la existencia de una combinación específica de atributos o beneficios para el consumidor, de modo que contribuye a estructurar y diferenciar la oferta en la mente del comprador (Martín, 2005).

Esta función tiene lugar gracias a las asociaciones mentales que es capaz de generar, es decir la imagen de marca (Aaker, 1991). Las marcas, por tanto, no se pueden concebir como simples nombres o logotipos, sino que representan las percepciones y las opiniones de los consumidores respecto de un producto y de los resultados del mismo, es decir, todo lo que el producto significa para los consumidores (Kotler et al., 2008).

Las ideas que puede evocar una marca se pueden referir a cuestiones directamente relacionadas con el producto (por ejemplo, sus propiedades, su calidad, tipo de usuarios, momentos de uso u origen), a aspectos relativos a la personalidad de la marca y a aspectos ligados a la organización (filosofía, cultura, valores de la organización que comercializa la marca). Algunas de estas asociaciones, y las relaciones existentes entre ellas, han sido objeto de numerosos estudios en el sector cárnico.

En lo referente a la calidad percibida, la literatura señala que la marca se configura como el indicador que informa al consumidor sobre las propiedades intrínsecas del producto. A este respecto, diversos estudios indican que las marcas inducen a una percepción de calidad significativamente mayor (Hui et al, 1995; Siret y Issanchou, 1996; Van Trijp et al., 1996; Calvo y Tudoran, 2008).

Cabe destacar también los estudios referentes a las asociaciones de origen, que se derivan de aspectos como el conocimiento que tiene el consumidor de las características socioculturales de la zona, su experiencia personal y los estereotipos existentes en torno a la misma (Roth y Romeo, 1992).

Las asociaciones de origen pueden condicionar de manera importante la imagen de marca global, a través de la poderosa influencia que ejercen sobre otro tipo de asociaciones (Yagüe y Jiménez, 2002). Así, pueden influir sobre la calidad percibida (Steenkamp, 1990; Bello y Gómez, 1996; Olaizola et al. 2001; Van Ittersum et al, 2001), debido al control de los sistemas de fabricación que subyacen en los distintivos geográficos de calidad, así como el supuesto "saber hacer" de determinadas zonas geográficas (por ejemplo, Castilla y León, Navarra, Aragón, etc.). Por otro lado, las asociaciones de origen también pueden desembocar en asociaciones ligadas a la personalidad peculiar de la marca caracterizada por una determinada cultura, tradiciones, etc. (Martínez y Jiménez, 2006) generando beneficios de tipo afectivo o de auto-expresión (Delamont, 1995; Obermiller y Spangenberg, 1989; Verlegh y Steenkamp, 1999). Téngase presente, no obstante, que para que se desencadenen los citados efectos es preciso, por un lado, que una proporción significativa del público objetivo conozca la región y, por otro, que dicha región sea capaz de suscitar asociaciones lo suficientemente claras y favorables (Van der Lans y Van Ittersum, 2001). 
En suma, el origen se convierte, en cierta manera, en un elemento aglutinador de distintos tipos de asociaciones, que simplifica la evaluación del producto y facilita el proceso de búsqueda de información (Wandell, 1997). Ello explica, en buena medida, la considerable importancia que los consumidores otorgan a esta variable a la hora de tomar sus decisiones de compra de cordero, a tenor de diversos estudios realizados tanto a nivel nacional (Sánchez et al., 2001; Bernabéu y Tendero, 2005; Sepúlveda et al., 2011) como internacional (Bernués et al., 2003).

\section{B. La marca como garantía}

Erdem y Swait (1998) señalan que la marca constituye la señal más fiable para el consumidor, dado que, al estar sometida a la supervisión y sanción por parte del mercado, compromete al oferente a cumplir sus promesas de calidad (Calvo y Tudorán, 2008). Esta garantía, además, es mayor cuanto más conocida es la marca, porque su propietaria no puede permitirse decepcionar al mercado y perder parte del capital de notoriedad acumulado.

La función de garantía es muy importante en el sector agroalimentario, dado que existen atributos de calidad como la salubridad, las propiedades nutricionales o la forma de producción que el consumidor no puede evaluar ni antes ni después del consumo. No en vano, en la calidad de los productos alimentarios, se pueden distinguir tres niveles (Cruz et al., 2004):

- Seguridad alimentaria: la calidad como resguardo de inocuidad, esto es, que el alimento se encuentre libre de contaminaciones que supongan una amenaza para la salud. Los estándares mínimos de seguridad que debe satisfacer un producto alimenticio son controlados por las Administraciones públicas y de obligado cumplimiento.

- Calidad nutricional: la calidad que se refiere a la aptitud de los alimentos para satisfacer las necesidades del organismo en términos de energía y nutrientes. Este factor ha adquirido gran relevancia para el consumidor informado que conoce el potencial preventivo de una dieta saludable y equilibrada.

- Calidad definida por los atributos de valor: estos atributos son factores que están más allá de la calidad básica nutricional o de inocuidad de un alimento, y diferencian los productos de acuerdo a sus características organolépticas y a la satisfacción del acto de alimentarse ligada a factores socioculturales, medioambientales, éticos, tradicionales, etc. Así se consideran elementos como el color o sabor de los alimentos, el respeto al medio ambiente a lo largo de la cadena productiva (por ejemplo, corderos ecológicos), o el respeto a las tradiciones (por ejemplo, corderos sacrificados por métodos tradicionales).

De estos tres niveles, la seguridad alimentaria se presenta actualmente como especialmente importante (Caswell, 2001), dada la progresiva pérdida de confianza de los consumidores en el sector agroalimentario en general, y en el cárnico en particular (Corcoran et al., 2001), impulsada por aquellos alimentos que han sido objeto de algún tipo de "escándalo" (Barrena et al. 2003).

La garantía de que un producto dado cuenta con una determinada combinación de atributos se puede tangibilizar, por tanto, mediante signos distintivos o marcas en los que subyace el compromiso del oferente, permitiendo reducir el riesgo percibido por los clientes en la compra (Wandell, 1997; Sánchez et al., 2001). 
Pero, además, la literatura especializada señala que la función de garantía puede verse reforzada por un aval procedente de una institución fiable y de prestigio, que actúa a modo de entidad certificadora (Albayrak y Gunes, 2010). La certificación es la acción llevada a cabo por una entidad pública o privada reconocida como independiente de las partes interesadas (Autoridad de Certificación), mediante la que se manifiesta que se dispone de la confianza adecuada de que un producto, proceso o servicio debidamente identificado es conforme con una norma u otro documento normativo especificado (un pliego o referencial en el que se detallan los estándares y requisitos exigidos). La observancia de los protocolos recogidos en los pliegos o referenciales da lugar a la concesión de un distintivo diferenciador, propiedad de la Autoridad de Certificación, con el que el producto accede a los mercados.

Muchos sistemas de certificación basan buena parte de su existencia en certificar que un producto guarda un determinado vínculo con una unidad territorial, un atributo de confianza que es altamente valorado en ciertos mercados. Este es el caso de las IGP (Identificación Geográfica Protegida), que amparan productos que tienen un vínculo con el medio geográfico al menos en una de las etapas del proceso de producción y transformación o elaboración, o las DOP (Denominaciones de Origen Protegidas) en las que el vínculo se produce en todas las fases del proceso.

Existen también distintivos creados al amparo de La Ley Española de Marcas (17/2001 del 7 de diciembre) denominados "marcas de garantía" que responden al objetivo de promocionar los productos agrarios de zonas o regiones específicas. Se trata de signos susceptibles de representación gráfica utilizados por una pluralidad de empresas bajo el control y autorización de su titular, que certifican que los productos o servicios a los que se aplican cumplen unos requisitos comunes, en especial, en lo que concierne a su calidad, componentes, origen geográfico, condiciones técnicas o modo de elaboración del producto o de prestación del servicio.

Las crisis alimentarias del sector cárnico han provocado un incremento de los estándares de la reglamentación técnico sanitaria y el impulso de programas de mejora de la calidad, promoviendo aspectos como el etiquetado facultativo de carne de cordero y cabrito (regulado mediante la resolución de 10 de septiembre de 2009 de la Dirección General de Recursos Agrícolas y Ganaderos).

Por etiquetado facultativo en los sectores ovino y caprino se entiende todo sistema de etiquetado amparado por un pliego de condiciones facultativo aprobado oficialmente, que proporcione al consumidor información veraz sobre características adicionales de los productos no incluidas en las normas de etiquetado mínimo obligatorio, y cuyo cumplimiento certifique un organismo independiente reconocido mediante un sistema de control. El etiquetado facultativo solo es de aplicación a la carne fresca, refrigerada o congelada de cordero o cabrito de edad inferior a cinco meses.

Por otra parte, la actividad certificadora puede recaer sobre distintas fases de la cadena de valor (producción, transformación/comercialización). Así, a modo de ejemplo, en el seno de la UE se ha iniciado un debate sobre las distintas opciones de etiquetado referentes al bienestar animal, todas ellas voluntarias. Una de ellas pasa por establecer un etiquetado voluntario en el que se reconozcan una serie de requisitos. Otra de ellas apuesta por establecer un sello comunitario único que se aplicaría a todos aquellos que cumplan con determinados criterios o también preparar una serie de guías para los sistemas de bienestar y calidad animal.

En definitiva, los sistemas de certificación permiten proporcionar una mayor garantía al consumidor, reduciendo el riesgo percibido y aumentando la confianza de los consumi- 
dores, tal como sugieren diversos estudios empíricos realizados al respecto. Así, un estudio realizado por Sánchez et al. (2001) en San Sebastián y Pamplona, pone de relieve que los distintivos de calidad de carne de ternera y ovino contribuyen a reducir la percepción de los consumidores de signos de insalubridad o inseguridad alimentaria. Barrera et al. (2003), por su parte, van más allá al mostrar que la recuperación del consumo vía certificación es posible en aquellos casos en los que el consumo se ha resentido como consecuencia de un problema de salubridad o crisis alimentaria.

Sepúlveda et al. (2010), por su parte, concluyen a partir de un estudio realizado en Zaragoza que los consumidores que son muy leales a la carne de cordero certificada (mediante IGP) asocian dicha certificación a un producto que ofrece más garantía y es más saludable. Los consumidores esporádicos, sin embargo, lo asocian a un producto que es objeto de un mayor control, pero no a un producto más saludable que proporciona una mayor garantía.

Obsérvese, por último, que, desde la perspectiva de nuestro análisis, las certificaciones de distinto tipo, como, por ejemplo, las denominaciones de origen, se encuadran también en el concepto de marca, dado que desempeñan las funciones esenciales que caracterizan a la misma (Bello y Calvo, 1998; Martínez y Jiménez, 2006).

La marca, en definitiva, trasciende al producto o a los sistemas de producción, los cuales pueden ser objeto de certificaciones de distinto tipo, integrando un conjunto de asociaciones mentales o significados de los que se deriva una proposición de valor diferenciada para el consumidor que puede tener una naturaleza funcional, emocional y de autoexpresión.

\section{La función asistencial y docente de la marca}

La marca asiste al comprador en el proceso de compra, simplificando dicho proceso, reduciendo el esfuerzo realizado en el mismo y, en definitiva, ayudándole a comprar de forma práctica. Esta función se puede concebir, en parte, como resultado de las dos funciones anteriormente expuestas, y también como resultado de la "función docente" que desempeñan las marcas. Como afirman Ollé y Riu (2009), las marcas destacan aquellos aspectos que necesitamos conocer para disfrutar de una categoría concreta. Por tanto, las marcas desempeñan el papel de profesores o difusores de conocimiento en sus respectivas categorías. Resulta reseñable el hecho de que en cada categoría suele existir una marca líder que enseña a comprar en función de determinados parámetros, los cuales son asimilados por los compradores, llegando a constituir creencias que se dan por sentadas. Por otro lado, cuantas más marcas intentan "enseñar a comprar" sus productos mayor es la percepción de diferencias por parte de los consumidores, evitando que el producto sea percibido como homogéneo o indiferenciado y aumentando la sensibilidad a las marcas. Si llevamos este planteamiento al sector ovino, las marcas podrían enseñar a los consumidores a comprar en función, por ejemplo, de las características que tienen distintos tipos de cordero, en función de los modos de producción (Mennecke et al., 2007), o de otros parámetros más emocionales (por ejemplo, apoyo a la ganadería local, etc.). Todo ello sin olvidar que la información proporcionada al consumidor debe ser accesible y relevante (sin sobrecargar al consumidor con información innecesaria o excesivamente técnica) (Wezemael et al., 2010). Se trata, en definitiva, de orientar al cliente en su proceso de compra, proporcionándole vías que faciliten la búsqueda de aquellas opciones que mejor se ajusten a sus necesidades. 


\subsection{La gestión de marcas y las redes de generación de valor del sector ovino}

El análisis efectuado hasta este punto, muestra el potencial que subyace en las marcas desde una perspectiva de generación de valor para los consumidores del mercado agroalimentario, y más específicamente, del ovino. Dicho potencial, no obstante, no tendría ningún valor práctico si los operadores del sector no fueran capaces de aprovecharlo, convirtiéndolo en resultados. Esa es precisamente la función que desempeña la gestión de la marca, que parte de un profundo conocimiento del mercado y del entorno y consta, básicamente, de la definición de una proposición de valor única, clara y diferenciada, y su posterior implementación mediante las correspondientes acciones de marketing (Aaker, 1991; Schmitt y Simonson, 1998, Kapferer, 2008, Ollé y Riu, 2009).

Para realizar estas tareas, resulta necesaria la colaboración y la implicación de los distintos operadores del sector que se sitúan a lo largo de la cadena de valor, que va desde la producción del cordero hasta la entrega del producto final al consumidor (Insch, 2008). De hecho, el valor transmitido por la marca dependerá, en buena medida, de la capacidad de la cadena de valor para combinar sus recursos de forma que se realice una única proposición de valor al cliente (Webster, 1992; Mizik y Jacobson, 2003). La literatura sugiere, además, que el trabajo conjunto con otros miembros de la cadena de valor permite una mejor adaptación de la oferta a las necesidades de los consumidores y, en última instancia, incrementar el valor proporcionado a los mismos (Taylor, 2006; Zokaei y Simons, 2006; Pérez et al. 2009).

La creación de valor mediante una adecuada gestión de marcas conlleva, por tanto, la búsqueda de colaboración a lo largo de la cadena de valor, con el propósito de crear redes de generación de valor, es decir, redes de operadores que colaboran para realizar una oferta al mercado y mejorar el funcionamiento del sistema (Kotler y Armstrong, 2008).

Este planteamiento pone de relieve que la proposición de valor que subyace en una determinada marca debe proyectarse en primer lugar al interior de la cadena de valor (proyección interna de la marca), dado que sólo así será posible que los operadores implicados en la producción y comercialización de la misma comprendan su significado y sean capaces de proyectarlo al mercado de una manera coherente (proyección externa de la marca).

En suma, el resultado práctico que puede proporcionar la marca, como herramienta comercial dirigida a incrementar la competitividad del sector ovino vasco, está fuertemente ligado al modo en el que se articula el sector a la hora de crear marcas e implementarlas en el mercado. Esta es precisamente la cuestión que abordamos seguidamente, una vez delimitada la metodología de recogida y análisis de la información empleada en la parte empírica de nuestro estudio.

\section{METODOLOGÍA}

La información referente al sector del cordero de raza Latxa del País Vasco, se ha obtenido recurriendo tanto a fuentes de información secundarias como primarias:

La información secundaria que se ha recopilado incluye, entre otros aspectos, los datos generales del sector, estadísticas de producción, estudios sobre la distribución, datos de consumo, análisis de tendencias, normativa y reglamentaciones. Las fuentes de informa- 
ción a las que se ha recurrido han sido principalmente organismos oficiales y asociaciones sectoriales, así como las revistas y publicaciones más relevantes vinculadas al sector ovino.

Por otro lado, dada la escasez de estudios específicos referentes al sector ovino vasco, y con el propósito de cubrir los distintos niveles de la cadena de valor, ha sido necesario obtener información primaria del sector, para lo cual hemos empleado tres métodos de naturaleza cualitativa:

a) Focus Group: se han realizado dos dinámicas de grupo, una con responsables de explotaciones ovinas y otra con carniceros.

b) Entrevistas personales: se ha entrevistado a doce responsables de empresas situadas a distintos niveles de la cadena de valor (mayoristas, mataderos y grandes superficies).

c) Observación: esta técnica se ha empleado de forma complementaria a las anteriores, para comprobar sobre el terreno las estrategias comerciales seguidas en el sector (observación de precios, presentación del producto en el punto de venta, acciones de comunicación, etc.).

La metodología utilizada responde a la naturaleza exploratoria de nuestro trabajo y a la necesidad de obtener información compleja relativa a opiniones, percepciones, actitudes y motivaciones de los miembros del sector objeto de estudio. En lo referente a la planificación y desarrollo de las dinámicas, entrevistas y la observación, se han seguido los criterios establecidos en la literatura especializada. Para facilitar el análisis de la información obtenida, las sesiones y entrevistas han sido grabadas y trascritas, ordenando posteriormente los temas de acuerdo a los objetivos de la investigación.

\section{ANÁLISIS DE RESULTADOS}

\subsection{La estructura del sector del cordero de raza Latxa del País Vasco}

El modelo que se muestra en la figura 1 proporciona una visión sintética del sector del cordero de raza Latxa del País Vasco, haciendo manifiestas las relaciones de compraventa que se producen entre los tres niveles de la cadena de valor (producción, comercialización en origen, que incluye el sacrificio del ganado, y comercialización en destino).

Estas relaciones han sido clasificadas en tres tipos:

\section{A. Productor-consumidor}

Esta relación (identificada en el modelo con el número “1”) responde al planteamiento más básico, según el cual es el propio pastor el que vende directamente al consumidor final, o bien a algún carnicero, efectuando el sacrificio en su explotación. Esta actividad, se realiza de forma encubierta, toda vez que no están permitidos los sacrificios para la venta fuera de los mataderos oficiales. Sin embargo, las entrevistas mantenidas con diversos agentes de este mercado, nos indican que se sigue realizando en una proporción elevada. Otra variante de este sistema sería aquélla en la que el ganadero efectuara el sacrificio en un matadero y vendiera directamente el animal al consumidor final. 
Figura 1

Estructura del sector ovino de raza Latxa de la CAPV

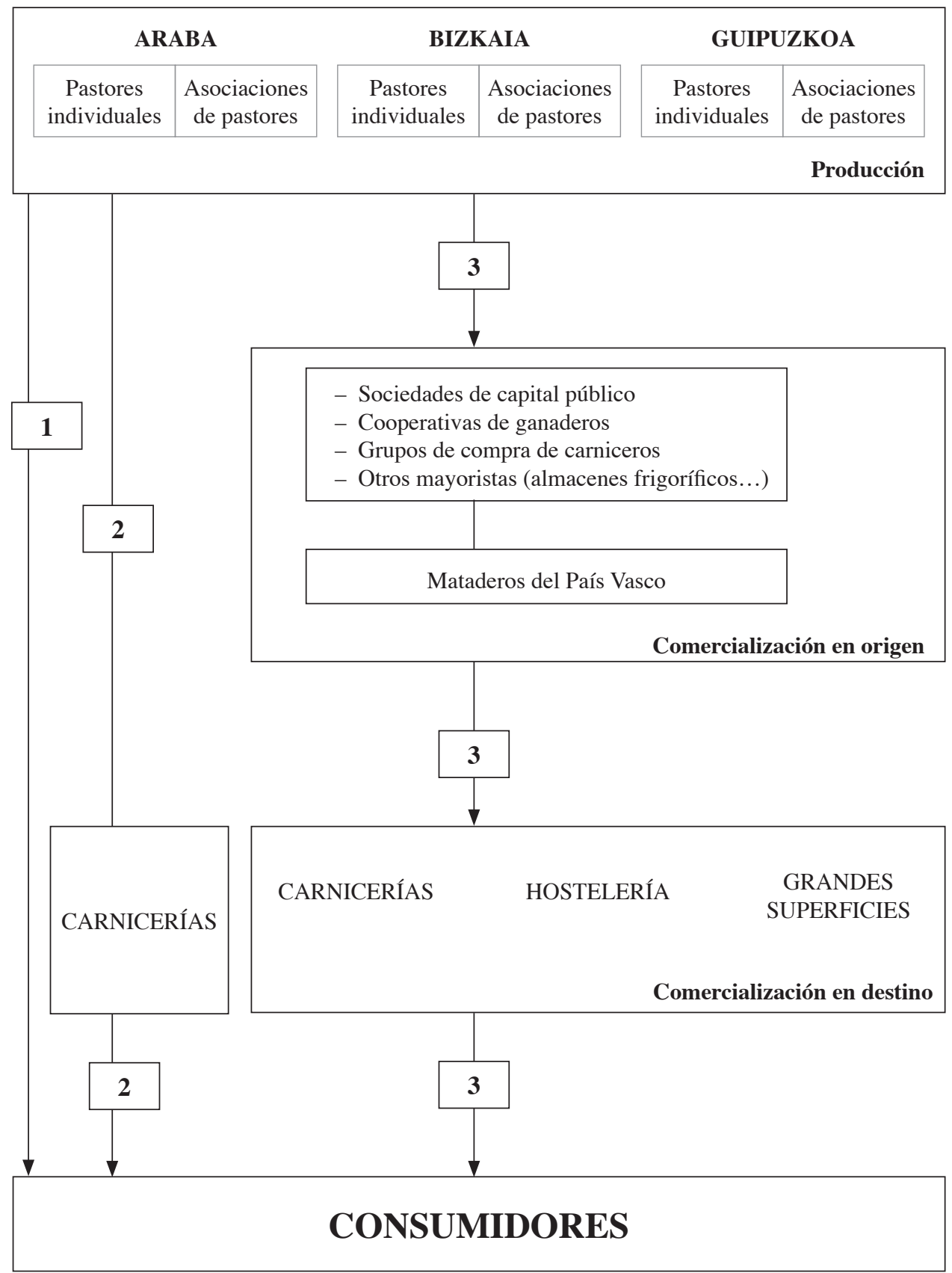

Fuente: elaboración propia 


\section{B. Productor-carnicero-consumidor}

En este tipo de compraventa (identificada en el modelo con el número “2”), el pastor no vende directamente el cordero al consumidor, sino que se lo vende a una carnicería, que es la que se encarga de la venta final del producto.

El pastor se encarga de transportar un lote relativamente pequeño de ganado hasta un matadero de su zona, a menudo haciendo uso de sus propios medios de transporte. Una vez allí, los corderos son sacrificados y transportados por el propio matadero hasta la carnicería correspondiente, la cual asume el coste del sacrificio. Se trata de un planteamiento tradicional que tiene un peso específico importante en el conjunto del sector.

\section{Productor-Comercializador en origen-Comercialización en destino-Consumidor}

El planteamiento tradicional que acabamos de explicar convive con planteamientos más modernos que se caracterizan por la compraventa de considerables volúmenes de cordero, haciendo uso de estructuras comerciales más complejas.

Estas son las dos principales características de este tipo de relación de compraventa, que se identifica en el modelo con el número " 3 ":

- Los productores agrupan su producción en torno a asociaciones o grupos de pastores

- Los corderos son adquiridos por distintos comercializadores en origen, los cuales fraccionan las grandes cantidades compradas en lotes más reducidos, en función de las necesidades de sus clientes (carnicerías, grandes superficies o establecimientos del sector hostelero dedicados a la venta final del producto). Las empresas que actúan como comercializadoras en origen son de naturaleza diversa, tal como se aprecia en la figura 1, y algunas de ellas cuentan con mataderos de su propiedad para el sacrificio del ganado.

En definitiva, el modelo que presentamos pone de manifiesto la existencia de múltiples "redes de generación de valor", formadas por operadores que colaboran al mismo nivel o a distinto nivel de la cadena de valor, con el fin de mejorar la producción y comercialización de la carne de cordero. Pero, lo relevante, desde la perspectiva de nuestra investigación, es que esa colaboración se ha extendido también al ámbito de la creación e implementación de marcas, tal como explicamos seguidamente.

\subsection{Las marcas del cordero lechal de raza Latxa del País Vasco}

Los problemas de seguridad que se han producido en algunos sectores cárnicos (vacuno, pollo, etc.) han generado un incremento de la demanda de productos de mayor calidad, que se identifican a través de distintos tipos de marcas (Sánchez et al., 2001).

En el sector ovino, no obstante, la inquietud provocada por la inseguridad alimenticia ha sido inferior, apreciándose una menor sensibilidad a las marcas. Esto se ha traducido en una menor presencia de carne de cordero con marca en los puntos de venta.

Circunscribiéndonos al sector ovino de raza Latxa del País Vasco, las marcas que actualmente existen son el resultado de la actividad desarrollada por diversas redes de generación de valor constituidas a partir de dos modelos distintos: el modelo corporativo y el no corporativo. 
El modelo corporativo se caracteriza porque la red de generación de valor se construye en torno a un determinado operador del sector, que es el propietario de la marca y toma todas las decisiones correspondientes a su gestión y comercialización.

El modelo no corporativo, por su parte, da lugar a una red de generación de valor que no se constituye en torno a un operador del sector, sino en torno a una institución gestora de la marca que actúa a modo de entidad certificadora. Este modelo tiene un carácter más transversal, porque no gira en torno a un determinado operador del sector (productor, transformador o comercializador).

La tabla 1 muestra las principales marcas que integran cada grupo ${ }^{3}$, las cuales analizamos a continuación tratando de hacer explícitas las redes de generación de valor que en ellas subyacen.

Tabla 1

Principales marcas del sector ovino del País Vasco y sus características

\begin{tabular}{|c|c|c|c|}
\hline MARCA & DISTINTIVO & $\begin{array}{c}\text { PROPOSICIÓN } \\
\text { DE VALOR }\end{array}$ & MODELO DE RED \\
\hline
\end{tabular}

Bizkaiko Bildotsa

\begin{tabular}{llll}
\hline Urkaiko & $\begin{array}{l}\text { Innovación, adapta- } \\
\text { ción a necesidades } \\
\text { actuales }\end{array}$ & Corporativo \\
\hline $\begin{array}{l}\text { Euskal esne bildotsa/ } \\
\text { Cordero del País Vas- } \\
\text { co con Euskolabel }\end{array}$ & $\begin{array}{l}\text { Calidad y origen } \\
\text { certificadas }\end{array}$ & No corporativo \\
\hline $\begin{array}{l}\text { Cordero lechal } \\
\text { ecológico }\end{array}$ & Producto ecológico & No corporativo \\
\hline
\end{tabular}

Fuente: elaboración propia

\footnotetext{
${ }^{3} \mathrm{La}$ importancia en términos cuantitativos de estas marcas es muy dispar. La marca más relevante en este sentido es "Euskal esne bildotsa/Cordero del País Vasco" con Euskolabel, seguida a gran distancia por "Bizkaiko bildotsa" y el resto de marcas.
} 


\subsubsection{Modelo corporativo}

\section{A. "Bizkaiko Bildotsa"}

Esta marca comercial pertenece a "Erralde Durangoko Hiltegia, S.L.", una sociedad mercantil de capital público creada por diversos ayuntamientos de Bizkaia con el propósito de proteger los intereses de los pastores del Territorio Histórico. Esta corporación desarrolla tareas de sacrificio y comercialización de corderos, tratando de pagar precios dignos a los pastores (miembros de ACOL) e inspirándose en el principio de "soberanía alimentaria", el cual engloba un modelo de producción agroecológico y circuitos cortos de producción-comercialización-consumo, en contraposición al sistema de producción intensivo y a gran escala que se apoya en las grandes superficies de distribución. La marca propugna, por tanto, la defensa del cordero autóctono, distribuido exclusivamente a través de carnicerías y restaurantes del territorio y producido y sacrificado de modo tradicional.

Respecto a la presentación del producto en el punto de venta, los corderos que cumplen las características organolépticas requeridas, portan dos etiquetas de la marca "Bizkaiko Bildotsa". Sin embargo, aquellos corderos que no presentan la suficiente grasa, tienen golpes o un peso poco equilibrado ( $10 \%$ de la producción) portan una sola etiqueta. El cordero no se presenta envasado y el peso del cordero no afecta negativamente en el proceso de clasificación de los mismos.

Los precios que perciben los pastores en cada una de las fases de la campaña se definen previamente, estableciendo una distinción entre aquellos que portarán una o dos etiquetas de la marca. Cabe observar que los pastores asociados a Erralde obtienen comparativamente mejores precios que otros que no forman parte de estructuras tan integradas. Por otra parte, los corderos adquiridos por la sociedad se sacrifican en sus propias instalaciones, asumiendo además la labor de comercialización a carnicerías. Estos costes de sacrifico y comercialización se repercuten al precio final del producto.

Erralde no dispone por el momento de estudios sobre la notoriedad y la imagen de la marca "Bizkaiko Bildotsa". Sus responsables consideran, no obstante, que es una marca de notable popularidad y que han conseguido transmitir la esencia de la marca. Algunas asociaciones que conforman su identidad de marca están ligadas al producto, más concretamente, la categoría de producto a la que pertenece (cordero lechal), su elevada calidad y su origen (Bizkaia). Pero también pretende suscitar asociaciones ligadas a la organización que lo comercializa, la cual se caracteriza por emplear el sistema de faenado tradicional y por tener una filosofía muy concreta, que se sustenta en torno al concepto de "soberanía alimentaria" y el apoyo a los pastores y carnicerías de Bizkaia.

De estas asociaciones se deriva que la proposición de valor de esta marca puede tener un componente emocional e incluso de autoexpresión considerables, que va más allá de atributos meramente funcionales. Erralde dispone de un presupuesto modesto para dar a conocer la marca "Bizkaiko Bildotsa" e implementar su identidad. No obstante, los problemas legales a los que se ha enfrentado desde su constitución ${ }^{4}$, así como el contexto en el

\footnotetext{
${ }^{4}$ El Gobierno Vasco se ha opuesto, sin éxito, al registro legal de la marca, al considerar que ésta hacia un uso irregular de una mención geográfica, pudiendo inducir a error al consumidor. Este litigio legal fue objeto de un considerable seguimiento por parte de los medios de comunicación.
} 
que ha surgido la empresa, le han otorgado una publicidad gratuita que, posiblemente, ha redundado en su notoriedad. Resulta reseñable también la notoriedad conseguida gracias a los eventos organizados para promocionar la marca en torno a acontecimientos de relevancia, como por ejemplo, la jornada gastronómica-festiva en el Arenal de Bilbao con motivo del partido de la Supercopa entre el Athletic de Bilbao y el FC Barcelona.

La red de generación de valor que da origen a la marca "Bizkaiko Bildotsa", por tanto, gira en torno a un operador del sector, "Erralde Durangoko Hiltegia, S.L." (claramente identificado en el logotipo de la marca) que ha alcanzado acuerdos de producción y distribución con pastores, carnicerías y restaurantes de Bizkaia con el fin realizar una proposición de valor basada en la filosofía anteriormente descrita.

\section{B. "Urkaiko"}

Esta marca identifica a una cooperativa de ganaderos del valle del Urola que busca soluciones de comercialización alternativas con el desarrollo de líneas de productos transformados y envasados de alta calidad, proporcionando formatos y presentaciones más acordes a los gustos y necesidades de la clientela actual. Entre estos productos ocupa un puesto destacado el cordero asado de marca "Urkaiko". Se trata de un producto "Delicatessen" consistente en un cuarto de cordero lechal asado, envasado al vacío, de aproximadamente $1,4 \mathrm{Kg}$, y de fácil preparación, ya que basta con calentarlo en el horno veinte minutos. El producto se presenta en una bolsa de tela con ilustraciones de gran calidad, comercializándose también en un formato específico para hostelería con cajas de dos o cuatro cuartos. La distribución y promoción de esta marca se realiza por Internet, en una tienda virtual creada conjuntamente con una asociación ganadera del sector porcino. La empresa realiza entregas diarias del producto a través de furgonetas y camiones para no romper la cadena de frío y mantener las características del producto en perfectas condiciones para su entrega en el domicilio del cliente (básicamente empresas del sector de la hostelería). El valor añadido al producto explica el precio comparativamente elevado que presenta el producto.

La red de generación de valor que subyace en esta marca innovadora está constituida por una empresa que integra toda la cadena de valor desde la producción hasta la venta final al cliente (esta cooperativa de ganaderos dispone de un matadero y una estructura de distribución propios). Esta circunstancia facilita considerablemente la proyección coherente de la proposición de valor de la marca, dado que permite ejercer un mayor control sobre la misma.

\subsubsection{Modelo no corporativo}

\section{A. "Euskal Esne Bildotsa / Cordero lechal del País Vasco" con Eusko Label (Kalitatea fundazioa)}

"Euskal Esne Bildotsa / cordero del País Vasco" es una marca comercial que aparece acompañada de la marca de garantía "Eusko Label". Su propietaria es la "Fundación Kalitatea Fundazioa", una entidad vinculada al Gobierno Vasco que se encarga del control y 
certificación de la mismas (garantizando el origen, la calidad, seguridad y autenticidad de los productos a los consumidores), así como de su dinamización y promoción.

La marca de garantía, cuyo signo gráfico es la "K" de "Kalitatea" ("calidad" en euskera), sirve para identificar y distinguir aquellos productos agroalimentarios producidos, transformados y/o elaborados en la Comunidad Autónoma del País Vasco (CAPV), cuya calidad, especificidad o singularidad superan la media general. En lo relativo al cordero, el reglamento técnico de este distintivo establece que la certificación de calidad "Euskal Esne Bildotsa" con Eusko Label se extenderá a los corderos lechales de raza Latxa o Carranzana que hayan sido producidos, sacrificados y despiezados en la CAPV y que cumplan determinados requisitos en cuanto a edad (entre 21 y 35 días) y peso (entre 5 y 8 kilogramos con cabeza y asadura), así como en cuanto a perfil, grasa externa y cavitaria, color, consistencia y humedad de la carne.

Los corderos de esta marca se comercializan con cuatro etiquetas, una en cada cuarto, donde se indica el matadero, la fecha de sacrificio, el número de control y la garantía de Eusko label. El reglamento técnico de la marca incluye también la posibilidad de comercializar el producto envasado, siempre y cuando el despiece y envasado se realice en salas autorizadas.

En la comercialización en origen de la marca intervienen multitud de empresas (la mayoría de los comercializadores que aparecen en el modelo de la figura 1), y en comercialización en destino principalmente carnicerías y, en menor medida, grandes superficies. Ello explica, en parte, las grandes diferencias en precios que pueden existir entre un municipio y otro, e incluso entre establecimientos de una misma localidad. La entidad gestora de la marca afirma no intervenir en la fijación del precio final del producto, en aras al respeto al libre comercio. Por otro lado, resulta reseñable que, de acuerdo a la observación realizada, no parecen existir diferencias significativas entre los precios del cordero lechal con distintivo Eusko Label respecto a aquel que no lo tiene.

Esta marca goza de un reconocimiento prácticamente universal, si bien la notoriedad del cordero lechal con ese distintivo es menor (notoriedad sugerida del $81 \%$ en 2009, según datos proporcionados por la entidad). El posicionamiento de "Eusko label" está vertebrado a partir de los siguientes atributos: productos vascos, de caserío, de calidad superior y con respaldo institucional (Gobierno Vasco).

En cuanto a las señales emitidas al mercado, los gestores de la marca han tratado durante los últimos años de reorientar la gestión de la identidad de la marca "Eusko Label", potenciando determinadas asociaciones de marca y diseñando alternativas para una mejor implementación de dicha identidad. Entre ellas cabe citar el rediseño del logotipo para hacerlo más claro, moderno, ligero y simple, la unificación de la imagen visual de todos los productos amparados por la marca de garantía y la comunicación de la nueva imagen y arquitectura para conseguir un mayor equilibrio en el conocimiento de todos los productos y ganar en eficacia. Las campañas de comunicación realizadas durante los últimos años han incluido publicidad (televisión, publicidad exterior, publicidad en el punto de venta, etc.) promoción de ventas (folleto promocional dentro de los envases, y sorteos) y marketing directo dirigido al consumidor, intermediarios y restaurantes. En el caso específico del cordero lechal, durante los últimos años se han realizado distintas actividades dirigidas a promocionar la marca "Euskal Bildotsa" entre consumidores, productores y carniceros (fiesta del cordero lechal con Eusko Label, sorteos de viajes, etc.). 
En lo referente a la red de generación de valor, cabe recordar la multitud de empresas que intervienen en la comercialización de la marca. Esto hace que tenga un carácter más transversal, siendo muchos los operadores relacionados con la marca, lo que complica considerablemente la proyección interna y, por consiguiente, externa de la misma. Según las entrevistas mantenidas con responsables de la organización, aunque la entidad no conoce el número total de establecimientos en los que finalmente se comercializa la marca, trata de velar por su imagen, amonestando a aquellos operadores que, de acuerdo a sus informaciones, han realizado alguna acción que pueda resultar lesiva para la imagen de la marca. Por otro lado, ha creado una página web (www.beeee.net) dirigida a distintos niveles de la cadena de valor (pastores, carniceros y consumidores) con el fin de poner de relieve la proposición de valor de la marca y motivar mediante acciones de promoción.

\section{B. Cordero lechal ecológico (ENEEK)}

ENEEK es el sello del Consejo de Agricultura y Alimentación Ecológica de Euskadi que portan aquellos productos elaborados de acuerdo a los criterios de la agricultura y ganadería ecológicas, los cuales son objeto de un control específico por parte de la citada entidad. La producción ecológica responde a una motivación específica, tanto de los productores como de los consumidores que adquieren sus productos, ligada al respeto al medioambiente y la preservación de los recursos naturales. La ganadería ecológica está vinculada a la tierra, tiene un enfoque extensivo, se basa en una alimentación ecológica, sobre todo de la misma explotación, restringe la utilización de medicamentos y pone especial atención en el bienestar animal. La agricultura y ganadería ecológicas promueven sistemas de producción perdurables, buscando la autosuficiencia y el ahorro energético.

La marca, por tanto, tiene un carácter transversal dado que no se vincula a ningún operador en concreto, sino a una forma de producción específica sometida a un proceso de certificación. Desde una perspectiva de implementación de la marca, el Consejo de Agricultura y Alimentación Ecológica de Euskadi desarrolla acciones básicas (página web, campañas publicitarias,...) dirigidas a lograr una mayor notoriedad, dar a conocer la proposición de valor de la marca y, en definitiva, reforzar la demanda de productos ecológicos. En lo referente al cordero, se trata de un mercado todavía muy poco desarrollado en el País Vasco, por lo que tan sólo una decena pastores trabajan en este ámbito, comercializando el producto de forma directa a clientes habituales. El contacto directo de los productores con los consumidores les otorga una oportunidad extraordinaria para realizar una transmisión clara y coherente de la proposición de valor de la marca, aunque no parece existir en el sector una sensibilidad clara hacia la marca como instrumento comercial.

\section{IMPLICACIONES TEÓRICAS Y DE GESTIÓN: REFLEXIONES SOBRE LAS ESTRATEGIAS DE MARCA EN EL SECTOR OVINO DEL PAÍS VASCO}

El marco teórico desarrollado en la primera parte de esta investigación, así como el análisis de las redes de generación de valor y las marcas existentes en el sector del cordero de raza Latxa del País Vasco, nos permiten realizar una serie de reflexiones dirigidas a incrementar la competitividad del sector. 
En el mercado ovino, al igual que en otros mercados del sector agroalimentario, las marcas no han concitado un interés generalizado ni desde el punto de vista de la oferta ni de la demanda. Así, observamos que una parte considerable de la carne de cordero envasada que se ofrece en grandes superficies se comercializa sin marca alguna y sin hacer ninguna mención al origen del producto o a otras características del mismo. Esta situación también es aplicable al cordero vendido al corte en las carnicerías, aunque en este caso el producto cuenta con el apoyo de la información proporcionada por el carnicero a petición del cliente. El tratamiento comercial otorgado al cordero, por tanto, no ayuda a que sea percibido como un producto diferenciado. Todo ello revela que, en la práctica y en términos globales, los operadores del sector ovino, en general y del sector ovino vasco en particular, no están aprovechando suficientemente el potencial subyacente de la marca, como instrumento comercial.

El análisis empírico realizado en el sector ovino vasco muestra la existencia de varias redes de generación de valor que han comprendido la importancia estratégica de este instrumento comercial, y que han participado en la implementación de sus respectivas marcas. Las señales dirigidas al mercado, no obstante, resultan en general relativamente débiles, lo que nos lleva a plantear diversas reflexiones acompañadas de varias propuestas de actuación.

La literatura especializada señala que el valor percibido por los consumidores del mercado ovino está ligado en buena medida al origen del producto, dado que el origen es utilizado por el consumidor como un importante indicador de la calidad del producto. Por tanto, desde la perspectiva del sector ovino del País Vasco sería recomendable realizar un esfuerzo colectivo para vincular dicho origen a calidad, haciendo referencia por ejemplo, a la tradición y saber hacer de los pastores vascos, así como las características específicas de la raza Latxa derivadas de su origen geográfico. Este aspecto cobra una especial importancia si tenemos en cuenta que el cordero del País Vasco se enfrenta a una competencia proveniente de regiones próximas y asociada a un elevado nivel de calidad. A este respecto, consideramos que las acciones de comunicación específicas realizadas por las marcas del sector pueden contribuir positivamente a la proyección de una imagen global de "calidad" del cordero "autóctono vasco", siempre y cuando concedan el suficiente protagonismo a las citadas asociaciones de marca, estableciendo una conexión entre ellas.

Por otra parte, resulta reseñable que la competencia hace uso, en cierta medida, de indicadores geográficos de procedencia reconocidos en el ámbito público (por ejemplo, Lechazo de Castilla y León, Cordero de Navarra o Ternasco de Aragón). Dichas marcas certifican el origen y la calidad del producto con un aval procedente de una institución fiable, lo cual contribuye a reforzar la calidad percibida por el consumidor (Martínez y Jiménez, 2006). Este contexto competitivo, así como la importancia creciente de la función de garantía en los mercados agroalimentarios, ponen de relieve la importancia que tienen para el sector ovino vasco las marcas que certifican la calidad y origen, las cuales pueden adoptar distintas formas jurídicas. A este respecto, sería recomendable, desde un punto de vista estratégico, contar con una marca sólida en la que se pueda apoyar el conjunto del sector con el fin de proporcionar un valor diferencial frente a la competencia. La vocación transversal de este tipo de marca, no obstante, hace necesario que goce del suficiente apoyo en el sector, dado que, en caso contrario, difícilmente se conseguiría la necesaria adhesión de los operadores para darle el impulso que necesita. 
Esto no es óbice, sin embargo, para que los operadores del sector desarrollen marcas propias dirigidas a segmentos específicos del mercado que demandan una oferta diferenciada. Por ejemplo, consumidores que demandan productos delicatessen o gourmet, personas que buscan marcas acordes con una determinada filosofía, canal HORECA que demanda un determinado nivel de calidad y servicio, consumidores que buscan productos alimenticios innovadores y/o fáciles de preparar, etc. De hecho, la presencia de un mayor número de marcas que "aleccionan" a los consumidores con ofertas distintas (función docente), contribuye a una mayor percepción de diferencias por parte de éstos y, por tanto, más útil resulta la marca como instrumento comercial que permite simplificar el proceso de compra (función asistencial).

Para ello, es preciso tener presente que las marcas son mucho más que nombres y logotipos atractivos, son un conjunto de significados que permiten estrechar vínculos con los distintos segmentos del mercado. Estos significados pueden estar ligados, no sólo al origen o a la calidad, sino, según los casos, a atributos específicos del producto, a la organización que lo produce y/o a la personalidad de la marca, así como a los beneficios funcionales, emocionales y/o de autoexpresión que de ella se derivan.

En suma, y siguiendo la terminología empleada en el trabajo, tanto las marcas de carácter corporativo como las de carácter no corporativo pueden contribuir positivamente a la formación de una imagen diferencial del cordero lechal autóctono. No entendemos la diversidad de marcas como una amenaza sino como una oportunidad, porque, por un lado, contribuye a que el cordero sea percibido como un producto diferenciado y, por otro, las distintas marcas pueden ayudar, desde distintos frentes, a reforzar la imagen del cordero lechal de raza Latxa. Téngase en cuenta además, que la creación de distintas marcas facilita la penetración en distintos segmentos del mercado sin distorsiones de imagen.

Todas estas reflexiones tratan de poner de relieve el potencial que subyace en la marca para los operadores del sector ovino vasco. El beneficio real que de ella pueden obtener, sin embargo, está fuertemente condicionado por su capacidad para diseñar estrategias de marca adecuadas e implementarlas debidamente.

Así, la gestión de una marca no se limita a la gestión publicitaria o creativa de la misma, como a veces se piensa, sino que es una tarea mucho más compleja que parte de un profundo análisis del mercado, la competencia y la propia organización. Requiere una visión estratégica para definir la imagen que se desea proyectar y una habilidad operativa para transmitir esa imagen de una forma coherente y persuasiva. Para desarrollar estas tareas se necesita, además de los conocimientos de gestión adecuados, la colaboración y el compromiso a largo plazo, no sólo de todas las personas que conforman una misma organización, sino de todos aquellos miembros de la cadena de valor a través de los cuales se hace efectiva la promesa de la marca.

En este sentido, la integración de las distintas actividades de la cadena de valor desde la producción hasta la venta final facilita considerablemente la creación e implementación de marcas, dado que ofrece la posibilidad de conocer de primera mano las necesidades de los consumidores, así como controlar la promesa y entrega de valor final que se realiza a los mismos, permitiendo estrechar vínculos con ellos. Cuando no se da tal circunstancia, la complejidad de la gestión de la marca se acentúa considerablemente, siendo necesario en cualquier caso suscitar la motivación y colaboración necesarias en el seno de la red de generación de valor para que todos sus miembros asimilen el significado de la marca 
(proyección interna de la marca) y actúen en consonancia, proyectando adecuadamente la identidad de la misma (proyección externa).

Los contactos mantenidos con agentes del sector nos indican que, en términos generales, la colaboración entre operadores constituye todavía una asignatura pendiente. Por tanto, consideramos necesario impulsar, mediante la coordinación de la gran cantidad de organismos públicos y privados existentes en el sector, una cultura de colaboración que permita la formación de redes de generación de valor capaces de desarrollar marcas sólidas. Asimismo, se considera también conveniente incrementar la formación en materia de gestión de marcas.

Por último, y desde una perspectiva de gestión de marcas más avanzada, las redes de colaboración podrían extenderse al ámbito del co-branding, consistente en la combinación de distintas marcas del sector con el fin de desarrollar sinergias e incrementar el valor percibido por el mercado. Entre las acciones de este tipo podrían figurar las siguientes:

a) Combinación de marcas de tipo corporativo y no corporativo. De acuerdo a este planteamiento, una marca de carácter transversal (no corporativo), podría actuar a modo de marca paraguas dirigida a realizar una proposición de valor básica y respaldar a la marca específica (de tipo corporativo), la cual suscitaría asociaciones de marca particulares.

b) Extensión de las redes de colaboración más allá de la propia categoría de producto: Se pueden realizar acciones de co-branding con empresas del mismo sector u otros sectores para incrementar la notoriedad y el número de asociaciones positivas vinculadas a la marca. Así, por ejemplo, se podrían realizar acciones conjuntas con la marca Idiazabal (cuyos quesos se producen precisamente con leche de oveja de raza Latxa), con marcas del sector de la restauración que ofrecen cordero autóctono en sus cartas, con marcas turísticas, etc.

\section{CONCLUSIONES FINALES}

La marca, como instrumento comercial, puede contribuir a aumentar el valor percibido por los consumidores a través de las funciones que desempeña. Así, ayuda a identificar y diferenciar el producto, proporciona una garantía a los consumidores y desarrolla una labor docente y asistencial. El aprovechamiento de ese potencial, sin embargo, exige una firme determinación para desarrollar las capacidades que exige la creación e implementación de marcas, creando redes de generación de valor que actúen de forma conjunta y coordinada con el fin de realizar una proposición de valor única, clara y diferenciada.

El estudio empírico llevado a cabo pone de relieve la existencia de determinadas redes de valor que apuestan por las marcas, desarrollando en la mayoría de los casos incipientes acciones de branding. El reto inmediato que se le presenta al sector, no obstante, es extender la cultura de colaboración, innovación y diferenciación que precisa la creación y gestión de marcas al conjunto del mismo, con el propósito de crear redes sólidas y profesionalizadas que permitan atender las distintas demandas del mercado.

Resulta reseñable que esta investigación ha sido realizada a partir del estudio de los operadores del sector y no de la demanda. Por tanto, como línea de investigación futura, proponemos realizar un exhaustivo análisis del mercado del cordero del País Vasco, con el 
propósito de detectar aquellos aspectos de la demanda que actuarían como factores moderadores del potencial que proporciona la marca al sector ovino vasco.

\section{BIBLIOGRAFÍA}

AAKER, D.A. (1991): Managing Brand Equity. Capitalizing on the Value of Brand Name, Free Press, New York.

ALBAYRAK, M. Y GUNES, E. (2010): "Implementations of geografical indications at brand management of traditional foods in the European Union", African Journal of Business Management, Vol. 4, nº 6, pp. 1059-1068.

ANDERSEN, E.S. (1994): The evolution of credence goods: a transaction approach to product specification and quality control, MAPP working paper, $\mathrm{n}^{\circ}$ 21, Aarhus: The Aarhus School of Business.

ANDERSON, J.C. Y NARUS, J.A. (1999): Business Marketing Management: Understanding, Creating, and Delivering Value, Prentice-Hall, Upper Saddle River, NJ.

BARRERA, R.; SANCHEZ, M.; GIL, J.M.; GRACIA, A. Y RIVERA, L.M. (2003): "La certificación como estrategia para la recuperación de la confianza del consumidor en la adquisición de la carne de ternera", Economía Agraria y Recursos Naturales, Vol. 3, No 1, pp. 7-29.

BARRERA, R. Y SANCHEZ, M. (2003): "Análisis de los factores que influyen en la disposición a pagar un sobreprecio por los certificados de calidad en productos cárnicos", Revista Española de Investigación en Marketing ESIC, pp. 91-116.

BARROSO, C. Y MARTÍN, E. (1999): Marketing Relacional, Esic Editorial, Madrid.

BECKER, T. (1999): "Country of origin as a cue for quality and safety of fresh meat", Paper presented at $67^{\text {th }}$ EAAE Seminar: The Socio-Economics of Origin Labelled Products in Agrifood Supply Chains: Spatial, Institutional an Co-ordination Aspects, Le Mans.

BECKER, T. (2000): "Consumer perception of fresh meat quality: A framework for analysis, British Food Journal, Vol. 102, no 3, pp.158-176.

BELLO, L. Y CALVO, D. (1998): "Propuesta de un modelo positivo de compra de carne de ternera", Revista Española de Economía Agraria, $\mathrm{N}^{\circ}$ 183, pp. 201-220.

BELLO, L. Y GOMEZ, T. (1996): "Las denominaciones de origen y otras señales de calidad en las estrategias de diferenciación de los productos agroalimentarios. Una propuesta metodológica, Cuadernos Aragoneses de Economía, Vol. 6, № 2, pp. 43-54.

BERISTAIN, J.J. (2010): El efecto de la imagen de enseña sobre el valor de las marcas de distribuidor: un estudio aplicado a los hipermercados. Asociación Española de Centros Comerciales. Madrid.

BERNABÉU, R. Y TENDERO, A. (2005): "Preference structure for lamb meat consumers. A Spanish case study", Meat Science, $\mathrm{n}^{\circ}$ 71, pp. 464-470.

BERNUÉS, A., OLAIZOLA, A. Y CORCORAN, K. (2003): "Labelling information demanded by European consumers and relationships with purchasing motives, quality and safety of meat", Meat Science, no 65, pp. 1095-1106.

BERNUÉS, A., OLAIZOLA, A. Y CORCORAN, K. (2003): "Extrinsic attributes of red meat as indicators of quality in Europe: an application for market segmentation", Food Quality and Preference, $\mathrm{n}^{\circ}$ 14, pp. 265-276.

BLACKWELL, S.A.; SZEINBACH, S.L.; BARNES, J.H. GARNER, D.W. Y BUSH, V. (1999): “The Antecedents of Customer Loyalty: An Empirical Investigation of the Role of Personal and Situational Aspects on Repurchase Decisions", Journal of Service Research, Vol. 1, nº 4, pp. 362-375.

BUTZ, H.E.J. Y GOODSTEIN, L.D. (1996), "Measuring customer value: gaining the strategic advantage", Organizational Dynamics, Vol. 24, Winter, pp . 63-77. 
CALVO, S.; REINARES, P. Y FERNÁNDEZ, R. (1998): "Medición de la calidad percibida en los productos de consumo: evidencia empírica a través del análisis factorial", Congreso de AEDEM, Málaga, pp. 493-501.

CALVO, D. Y TUDORAN, A. (2008): "La importancia de la marca en la comercialización de productos perecederos: una aplicación empírica al sector vacuno", Revista Europea de Dirección y Economía de la Empresa, Vol. 17, No 1, pp. 151-166.

CASWELL, J.A. (2001): "Food safety and the U.S. consumer", 71 EAEE Seminar, Zaragoza, April.

CORCORAN, K.; BERNUÉS, A.; MANRIQUE, E.; PACCHIOLI, T.; BAINES, R. Y BOUTONNET, J.P. (2001): "Current consumer attitudes towards lamb and beef in Europe", Options Méditerranéennes, A46, pp. 75-79.

CRUZ, J.C.; LUCENA, B.; MÉNDEZ, M.A. Y CÁCERES, F. (2004): “Sistemas de certificación de la calidad en el sector agroalimentario español", Distribución y Consumo, n 76, pp. 23-41.

DARBY, M.R. Y KARNI, E. (1973): "Free competition and the optimal amount of fraud", Journal of Law and Economics, $\mathrm{n}^{\circ}$ 16, pp. 67-88.

DARDEN, W.R. Y SCHWINGHAMMER, J.K.L. (1985): “The influence of Social Characteristics on Perceived Quality in Patronage Choice Behavior", in Perceived Quality, J. Jacoby y J. Olson, eds. Lexington, MA: Lexington Books, pp. 161-72.

DELAMONT, S. (1995): Appetites and Identities: an Introduction in The Social Anthropology of Western Europe, London, Routledge.

DODDS, W.B. Y MONROE, K.B. (1985): "The Effect of Brand and Price Information on Subjective Product Evaluations", in Advances in Consumer Research, Vol 12, Elizabeth C. Hirschman and Morris B. Holbrook, eds. Provo, UT: Association for Consumer Research, pp. 85-90.

DOYLE, M. (1984): "New Ways of Measuring Value", Progressive Grocer-Value, Executive Report, pp. 15-19.

ERDEM, T. Y SWAIT, J. (1998): "Brand Equity as a Signaling Phenomenon”, Journal of Consumer Psychology, Vol. 7, n 2, pp. 131-157.

GRUNERT, K.G, LARSEN, H.H.MADSEN, T.K. Y BAADSGAARD, A. (1996): Market orientation in food and agriculture, Norwell, MA: Kluver.

GRUNERT, K.G., BREDAHL, L. Y BRUNSO, K. (2004): "Consumer perception of meat quality and implications for product development in the meat sector- a review", Meat Science, ${ }^{\circ}$ 66, pp. 259-272.

HUI, J.; MCLEAN-MEYINSSE, E.; JONES D. (1995): "An empirical investigation of importance ratings of meat attributes by Lousiana and Texas consumers", Journal of Agricultural and Applied Economics, Vol. 27, n ${ }^{\circ}$ 2, pp. 636-643.

INSCH, A. (2008): "Triggers and processes of value creation in Australia's chicken meat industry", British Food Journal, Vol. 110, No 1, pp. 26-41.

INSTITUT DE L'ÉLEVAGE (2008): "Les filières ovines dans 1'UE. Des moutons bien mal gardés", Économie de l'élevage, $\mathrm{n}^{\circ} 383$.

JACOBY, J., OLSON, J.C. Y HADDOCK, R.A. (1971): "Price, brand name and product composition, charateristics as determinants of perceived quality", Journal of Applied Psychology, n 55, pp. $570-579$.

JOHANSSON, J.K. Y NEBENZAHL, I.D. (1986) : "Multinational production : effect on brand value", Journal of International Business Studies, Vol. 17, nº3, pp. 101-126.

JURIC, B. Y WORSLEY, A. (1998) : "Consumers' attitudes towards imported food products", Food Quality and Preference, Vol. 9, n 6, pp. 431-441.

KAPFERER, J.N. (2008): The new strategic brand management: creating and sustaining brand equity long term, Kogan Page, London.

KELLER, K.L. (1993): "Conceptualizing, Measuring and Managing Customer-Based Brand Equity”, Journal of Marketing, Vol. 57, January, pp.1-22.

KOTLER, P. Y ARMSTRONG (2008): Principios de Marketing, Pearson Educación, Madrid. 
LASSAR, W., MITTAL, B. Y SHARMA, A. (1995): "Measuring customer-based brand equity", Journal of Consumer Marketing, Vol. 12, $\mathrm{n}^{\circ}$ 4, pp. 11-19.

LEY 17/2008, de 23 de diciembre, de Política Agraria y Alimentaria, BOPV, no 250.

LOW, G.S. Y LAMB, C.W. (2000): "The measurement and dimensionality of brand associations", Journal of Product \& Brand Management, Vol. 9, nº 6, pp. 350-368.

MARTÍN GARCÍA, M. (2005): Arquitectura de marcas. Modelo general de construcción de marcas y gestión de sus activos, Esic Editorial, Madrid.

MARTIN, G.S. Y BROWN, T.J. (1990): "In search of brand equity: the conceptualization and measurement of the brand impression construct", Marketing Theory Applications, $\mathrm{n}^{\circ}$ 2, pp. 431-438.

MARTÍNEZ, M.P. Y JIMENEZ, A.I. (2006): "La potenciación del origen en las estrategias de marketing de productos agroalimentarios. Objetivos, situación e implicaciones, Boletín Económico de ICE, $\mathrm{N}^{\circ} 2880$.

MEDINA, O.; MÉNDEZ, J.L. Y RUBIO, N. (2001): "Calidad y precio en las marcas de fabricante y marcas de distribuidor: evidencias empíricas", Revista Española de Investigación de Marketing ESIC", no 124, pp. 91-124.

MENNECKE, B.E., TOWNSEND, A.M., HAYES, D.J. Y LONERGAN, S.M. (2007): "A study of the factors that influence consumer attitudes toward beef products using the conjoint market analysis tool", Journal of Animal Science, http://jas.fass.org/cgi/content/full/85/10/2639.

MIZIK, N. Y JACOBSON, R. (2003): "Trading off between value creation and value appropriation: the financial implications of shifts in strategic emphasis", Journal of Marketing, Vol. 67, January, pp. 63-73.

NEVID, J.S. (1981): "Effects of brand labelling on ratings of product quality, Perceptual and Motor Skills, n' 53 , pp. 407-410.

NORTHEN, J.R. (2000): "Quality attributes and quality cues. Effective communication in the UK meat supply chain, British Food Journal, Vol. 102, n 3, pp. 230-245.

OBERMILLER, C. Y SPANGENBERG, E. (1989): "Exploring the effects of origin labels: an information processing framework", Advances in Consumer Research, $\mathrm{n}^{\circ}$ 16, pp. 454-459.

OLAIZOLA, A.; BERNUES, A.; MANRIQUE, E. Y MAZA, M.T. (2001): "QQuality cues for lamb: identification of consumer profiles in Aragon (Spain)", 71 EAAE Seminar, Zaragoza, April.

OLLÉ, R. Y RIU, D. (2009): El nuevo Brand Management: cómo plantar marcas para hacer crecer negocios, Gestión 2000, Barcelona.

OLSON, J.C. Y JACOBY, J. (1972): "Cue utilization in the Quality Perception Process", in Proceedings of the Third Annual Conference of the Association for Consumer Research, M. Venkatesan, ed. Iowa City: Association for Consumer Research, pp. 167-79.

OUDE OPHUIS, P.A.M. (1994): "Sensory evaluation of 'free range' and regular pork meat under different conditions of experience and awareness, Food Quality and Preference, n ${ }^{\circ}$ 5, pp. 173-178.

OUDE OPHUIS, P.A.M. Y VAN TRIJP, H.C.M. (1995): "Perceived quality: a market driven and consumer oriented approach", Food Quality and Preference, n n 6, pp. 177-183.

PEREZ, C.; DE CASTRO, R. Y FONT I FURNOLS, M (2009): “The pork industry: a supply chain perspective", British Food Journal, Vol. 111, No 3, pp. 257-274.

POULSEN, C.S.,JUHL, H.J., KRISTENSEN, K., BECH, A.C., Y ENGELUND, E. (1996): "Quality guidance and quality formation, Food Quality and Preference, $n^{\circ}$ 7, pp. 127-135.

ROTH, M.S. Y ROMEO, J.B. (1992): "Matching product category and country image perceptions: A framework for managing country-of-origin effects", Journal of International Business Studies, Vol. 23, No 3, pp. 477-498.

SANCHEZ, M.; SANJUAN, A.I. Y AKL, G. (2001): "El distintivo de calidad como indicador de seguridad alimenticia en carne de vacuno y de cordero", Revista de Economía Agraria y Recursos Naturales, Vol. 1, N ${ }^{\circ}$ 1, pp. 77-94.

SCHMITT, B. Y SIMONSON, A. (1997): Marketing Aesthetics, Free Press, New York. 
SEPÚLVEDA, W.S., MAZA, M.T. Y MANTECÓN, A.R. (2010): "Factors associated with the purchase of designation of origin lamb meat", Meat Science, no 85, pp. 167-173.

SEPÚLVEDA, W.S., MAZA, M.T. Y PARDOS, L. (2011): "Aspects of quality related to the consumption and production of lamb meat. Consumers versus producers", Meat Science, ${ }^{\circ} 87, \mathrm{pp}$. 366-372.

SIMONS, D. Y ZOKAEI, K. (2005): “Application of lean paradigm in red meat processing”, British Food Journal, Vol. 107, № 4, pp. 192-211.

SIRET, F.; ISSANCHOU, S. (1996): "Pâté de campagne et fabrication traditionelle: effet de l'information sur l'attente et l'appréciation", Communication aux 8èmes Rencontres Scientifiques et Technologiques des Industries Alimentaires, Agoral, Dijon, pp. 357-363.

SPROTT, D.E. Y SHIMP, T.A. (2004): "Using product sampling to augment the perceived quality of store brands", Journal of Retailing, Vol. 80, pp. 305-315.

STEENKAMP, J.-B.E.M. (1989): Product Quality, Van Gorcum, Assen, The Netherlands.

STEENKAMP, J.-B.E.M. (1990): "Conceptual model of the quality perception process, Journal of Business Research, no21, pp. 309-333.

SZYBILLO, G.J. Y JACOBY, J. (1974): "Intrinsic Versus Extrinsic Cues as Determinants of Perceived Product Quality", Journal of Applied Psychology, Vol. 59, February, pp. 74-78.

TAYLOR, D.H. (2006): "Strategic considerations in the development of lean agri-food supply chains: a case study of the UK pork sector", Supply Chain Management: An International Journal, Vol. 11, $\mathrm{N}^{\circ}$ 3, pp. 271-80.

VAHIE, A. Y PASWAN, A. (2006): "Private label brand image: its relationship with store image and national brand", International Journal of Retail \& Distribution Management, Vol. $34, \mathrm{n}^{\circ}$ 1, pp. 67-84.

VAN DER LANS, I.A. VAN ITTERSUM, K., DE CICCO, A. Y LOSEBY, M. (2001): "The role of the región of origin and EU certificates of origin in consumer evaluation of food products", European Review of Agricultural Economics, Vol. 28, no 4, pp. 451-477.

VAN ITTERSUM, K., MEULENBERG, M.T.G., VAN TRIJP, J.C.M. Y CANDEL, M.J.J.M. (2001): "Certificates of origin and regional product loyalty", Working Paper, Wageningen University.

VAN TRIJP, H.; STEENKAMP, J-B.E.M.; MATH, J.J.M. (1996): "Quality labelling as instrument to create product equity: the case of IKB in the Netherlands", Agricultural Marketing and consumer behaviour in a changing world, Wierenga, B.; Tilburg, A.V.; Grunert, K.; Steenkamp, J-B.E.M.; Webel, M. Kluwer academic Publisher.

VERLEGH, P. Y STEENKAMP, J.-B.E.M. (1999): “A review and meta-analysis of country-oforigin research, Journal of Economic Psychology, Vol. 20, nº 5, pp. 521-546.

WANDELL, M. (1997): "Food labelling from a consumer perspective", British Food Journal, Vol. 99, $\mathrm{N}^{\mathrm{o}} 6$, pp. 212-219.

WEBSTER, F.E. JR. (1992): “The changing role of marketing in the corporation", Journal of Marketing, Vol. 56, October, pp. 1-17.

WEZEMAEL, L.V., VERBEKE, W., KÜGLER, J.O., BARCELLOS, M.D. Y GRUNERT, K.G. (2010): "European consumers and beef safety: Perceptions, expectations and uncertainty reduction strategies", Food Control, n ${ }^{\circ} 21$, pp. 835-844.

YAGÜE, M.J. Y JIMÉNEZ, A.I. (2002): "Estrategias de diferenciación en los mercados agroalimentarios: la percepción de la imagen de la Denominación de Origen", Investigación y Marketing, Vol. 76, pp. 31-36.

ZEITHAML, V.A. (1988): "Consumer perceptions of Price, Quality, and Value: A means-End Model and Synthesis of Evidence", Journal of Marketing, Vol. 52, Julio, pp. 2-22.

ZOKAEI, K. Y SIMONS, D. (2006): "Value chain analysis in consumer focus improvement", The International Journal of Logistic Management, Vol. 17, $\mathrm{N}^{\mathrm{o}}$ 2, pp. 141-62. 
